\title{
Premalignant melanosis of the conjunctiva and the cornea in xeroderma pigmentosum
}

\author{
A D A Paridaens, A C E McCartney, J L Hungerford
}

\begin{abstract}
Xeroderma pigmentosum is a rare autosomal recessive dermatosis. The neoplastic changes in sunlight-exposed areas of the skin and eyes may be related to the impaired replication of ultraviolet radiation-damaged DNA. A 38year-old Greek woman is reported with a mild form of xeroderma pigmentosum and primary acquired melanosis with atypia of her right limbal conjunctiva and cornea. The development of this precursor of conjunctival malignant melanoma in a xeroderma pigmentosum patient may support the putative role of sunlight exposure in malignant transformation of conjunctival melanocytes.
\end{abstract}

Xeroderma pigmentosum is an uncommon autosomal recessive actinic dermatosis which was first described in 1874 by Hebra and Kaposi. ${ }^{1}$ This progressive disease of the skin and mucous membranes is characterised by abnormal sensitivity to sunlight, premature skin ageing, abnormalities of pigmentation, and multiple neoplasms. ${ }^{2}$ Xeroderma pigmentosum frequently has ocular complications including photophobia, recurrent conjunctivitis, keratitis, keratoconus, lid abnormalities, and neoplasms. ${ }^{2-8}$ A subset of xeroderma pigmentosum patients exhibit neurological deficits and mental deterioration. $^{8}$

Xeroderma pigmentosum patients have a defect in the repair of DNA damage following exposure to ultraviolet radiation (UVR) ${ }^{9}$ which is associated with homozygosity for one of at least seven different mutations. ${ }^{10}$ Xeroderma pig-

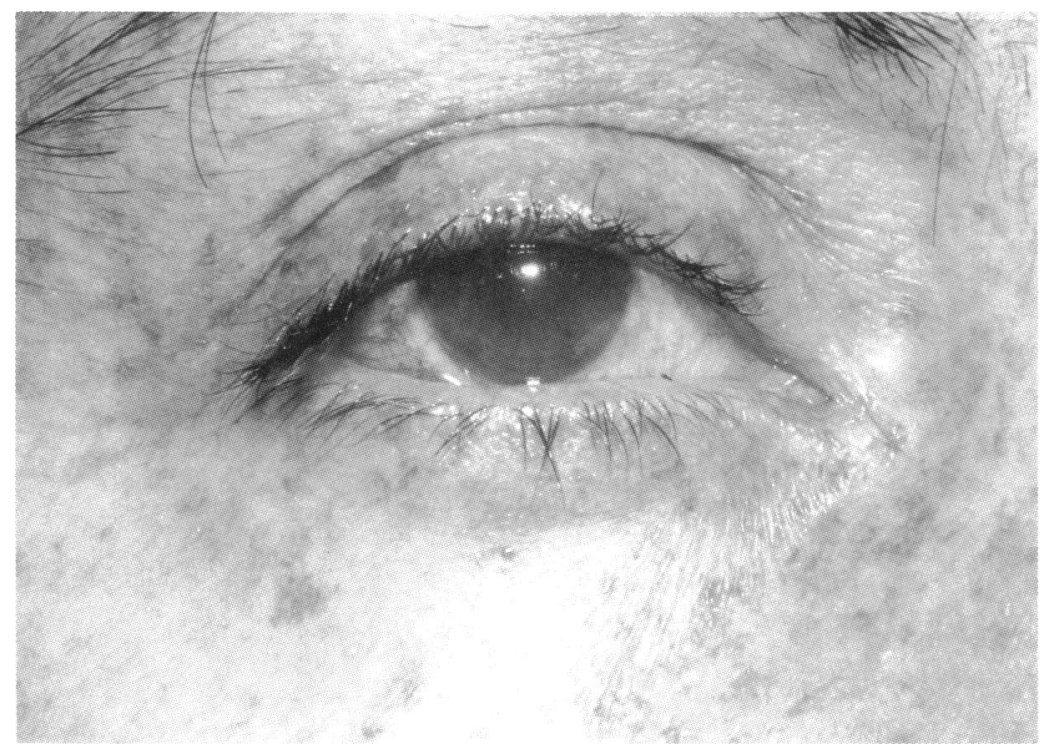

Figure 1 Right eye of a 38-year-old Greek woman with xeroderma pigmentosum. Note the extensive freckling and premature ageing of the skin and mild conjunctival hyperaemia. mentosum has a global distribution and tends to occur in the offspring of consanguinous parents.

Various types of ocular neoplasms in xeroderma pigmentosum patients have been reported. The most frequent tumour was squamous cell carcinoma followed by basal cell carcinoma. ${ }^{8}$ There have been rare reports of malignant melanoma, involving the eyelids, ${ }^{11}$ conjunctiva, ${ }^{4612}$ iris, ${ }^{13}$ and posterior uvea. ${ }^{14}$ is

Primary acquired melanosis with atypia is an acquired precancerous unilateral condition of the conjunctiva ${ }^{16}$ not arising as a result of long standing ocular inflammation, metabolic diseases, topical factors, or the patient's race. The melanocytes show atypical cytologic features including increased nuclear to cytoplasmic ratio upon microscopic examination.

We report a case of primary acquired melanosis with atypia affecting both conjunctiva and cornea of a 38-year-old Greek woman with xeroderma pigmentosum. The clinical and histopathological findings of this precursor of malignant melanoma, which to our knowledge has not been previously reported in xeroderma pigmentosum patients, are described.

\section{Case report}

In November 1987 a 38-year-old Greek woman with a mild form of xeroderma pigmentosum was referred by her ophthalmologist in Cyprus to the Oncology Department of Moorfields Eye Hospital. The patient had a history of a pigmented lesion of her right limbal conjunctiva which had been growing for 2 years. Her ocular history included recurrent conjunctivitis and photophobia since early childhood.

Two brothers and one sister expressed signs of xeroderma pigmentosum including skin abnormalities but no neurological deficit or mental deterioration. Two other sisters and a brother were clinically unaffected. The parents of the patient were not believed to be consanguinous. Her past medical history included appendicectomy and tonsillectomy.

On general examination widespread large freckles on the face (Fig 1), backs of the hands, arms, and neck were seen. The skin showed signs of loss of elasticity, telangiectasia, and atrophy. On the lower lip an erosive lesion with clinical characteristics of squamous carcinoma was noted.

The unaided visual acuity was $6 / 5$ in the right, and $6 / 9$ in left eye. Examination of the right eye showed a circumscribed flat pigmented conjunctival lesion extending round the temporal limbus (Fig 2) and exhibiting invasion into the superficial layers of the corneal epithelium (Fig 3). The corneal invasion extended to the temporal pupil margin. Increased vascularity was noted 


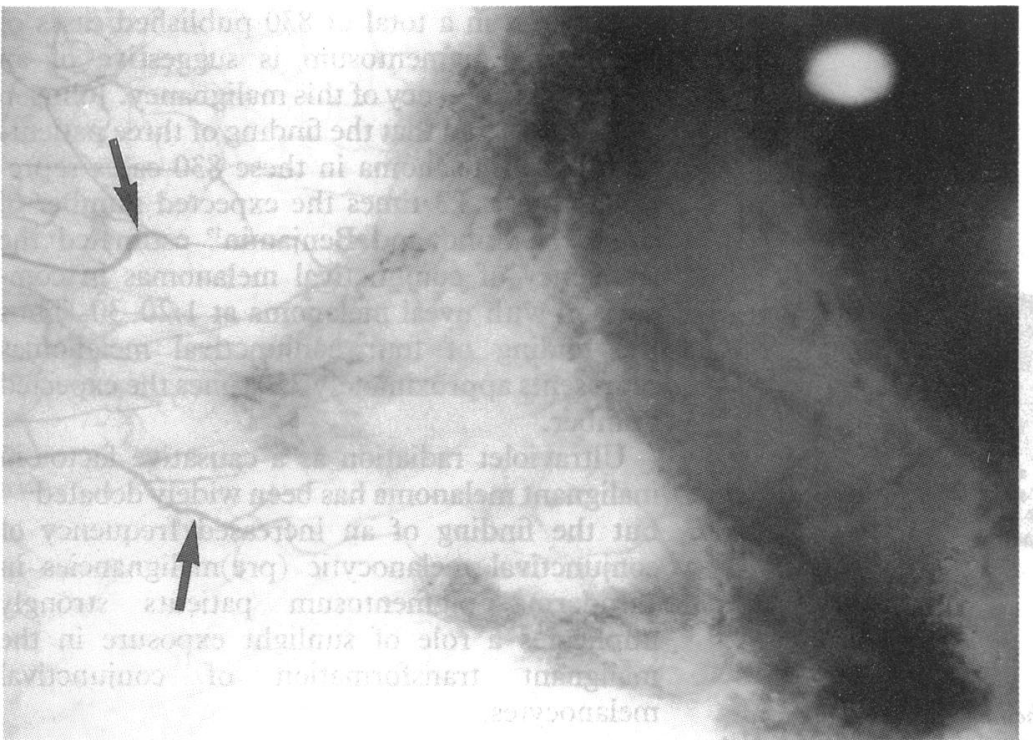

Figure 2 Detail of the right temporal limbus showing an area of flat conjunctival melanosis extending into the cornea. Note the feeder vessels (arrows).

round the limbal lesion which was not tethered to underlying sclera. The left eye and the remainder of the conjunctiva of the right eye were free from melanosis. In both eyes there was mild conjunctival hyperaemia and early development of pterygium.

The pigmented conjunctival lesion was resected en bloc with a lamella of underlying sclera and cornea. The affected corneal epithelium was removed using absolute alcohol. Triple freeze cryotherapy was subsequently applied to the limbal wound bed.

Histopathological examination of the corneal epithelium (Fig 4) showed an area of melanocytic proliferation maximal in the basal cell layer and with minor invasion of the more superficial epithelial layers. The biopsy of conjunctiva and limbus (Fig 5) showed much more widespread melanosis with in some areas considerable migration of atypical melanocytes into the epithelium. These findings were compatible with a diagnosis of primary acquired melanosis with atypia.

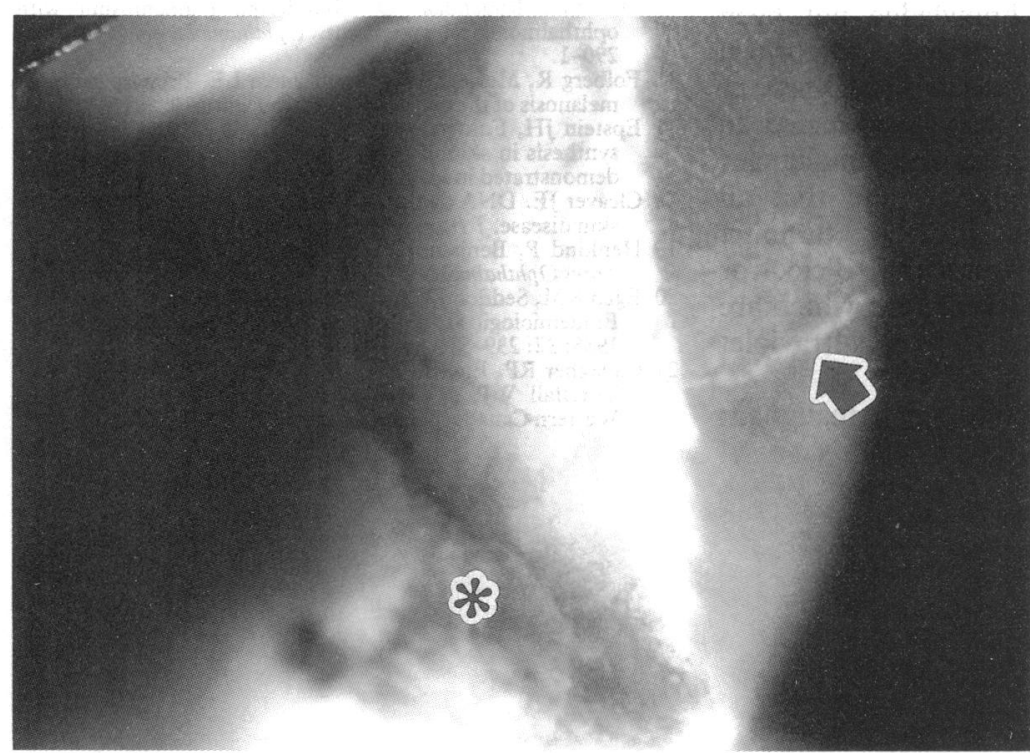

Figure 3 Lateral slit-lamp photograph of the right temporal limbus and cornea showing the corneal extension (arrow) of the conjunctival primary acquired melanosis ( ${ }^{\star}$ ).
In January 19881 month after treatment the conjunctiva had healed well and the cornea had re-epithelialised. In the meanwhile her lower lip lesion had been biopsied and histological examination confirmed the clinical diagnosis of squamous cell carcinoma.

When the patient was seen again in September 1988 the right eye including conjunctiva and cornea showed no signs of recurrence. For further ophthalmic follow-up she has been seen by her referring ophthalmologist in Greece from whom we have not heard since 1988 .

\section{Discussion}

Several studies ${ }^{917}$ have demonstrated an impaired replication of UVR damaged DNA in cells of xeroderma pigmentosum patients. This defect may be aetiologically linked to the various abnormalities in UVR exposed areas of these patients including atrophic and neoplastic changes.

In comparison with the general population xeroderma pigmentosum patients have an increased incidence of primary skin and ocular neoplasms such as basal and squamous cell carinomas and papillomas. The relative frequency and the biological nature of these tumours however are similar to those of normal individuals. Therefore xeroderma pigmentosum is used as a model for studying actinic carcinogenesis.

In an extensive review of 830 published cases of xeroderma pigmentosum by Kraemer et $a l^{8}$ $97 \%$ of basal cell and squamous cell carcinomas and $65 \%$ of cutaneous malignant melanomas occurred on the face, head and neck, all sunlight exposed sites, compared with $80 \%$ and $20 \%$ respectively in the general US population. Ocular tissues that are exposed to ultraviolet radiation include the eyelids, the conjunctiva, the cornea, and the inferior iris. The ocular abnormalities including neoplasms in xeroderma pigmentosum patients are generally limited to these areas. These findings implicate a role of sunlight exposure in the aetiology of these tumours.

Conjunctival malignant melanoma has been rarely described in patients with xeroderma pigmentosum. In $1948 \mathrm{Saebo}^{4}$ reported a 17year-old. Caucasian woman with a recurrent pigmented corneolimbal tumour which was clinically diagnosed as 'melanomalignoma'. There had been a dark spot in the affected eye for several years before the onset of tumour growth. It is of interest that in this case the diagnosis of this neoplasm preceded the diagnosis of xeroderma pigmentosum. In 1962 Jensen $^{12}$ described a case of a limbal malignant melanoma arising from a pre-existing naevus occurring in 14-yearold Greenlander with xeroderma pigmentosum. In 1965 El-Hefnawi and Mortada ${ }^{6}$ reported a 13year-old Egyptian boy with a biopsy proven 'melanocarcinoma' of the limbus and a 14-yearold Egyptian girl with an advanced conjunctival melanoma with invasion of the whole orbit and the base of the skull. The authors did not comment on any possible precursor.

Although primary acquired melanosis with atypia might have been present in some of above 

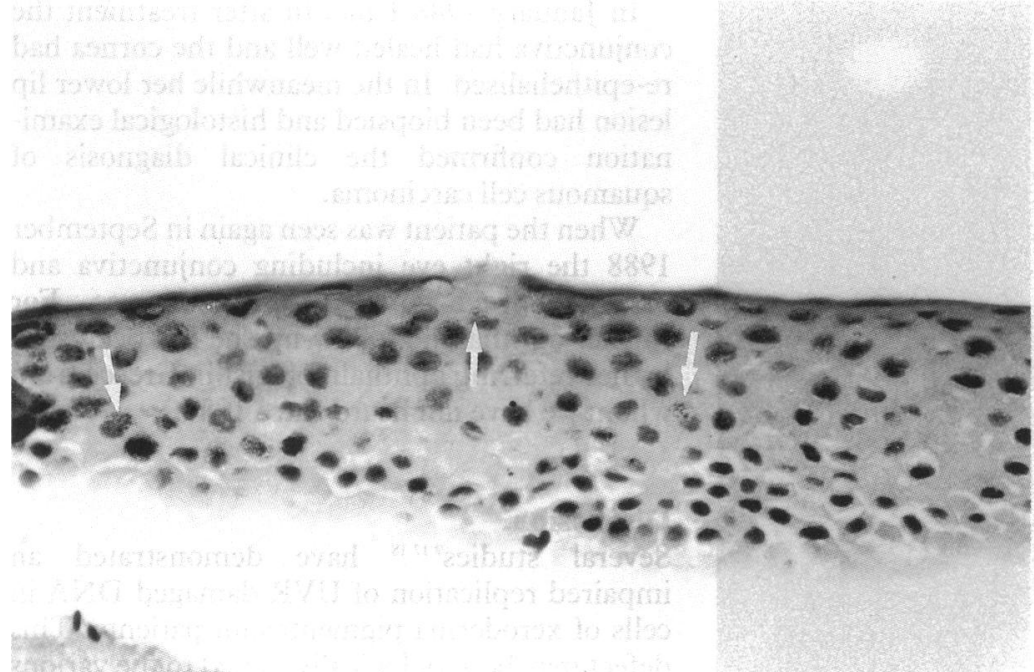

Figure 4 Histological examination of the affected corneal epithelium showed melanocytic proliferation involving both the basal cell layer and the more superficial epithelial layers. Note the presence of granular black pigment in the cytoplasm of the melanocytes (arrows).

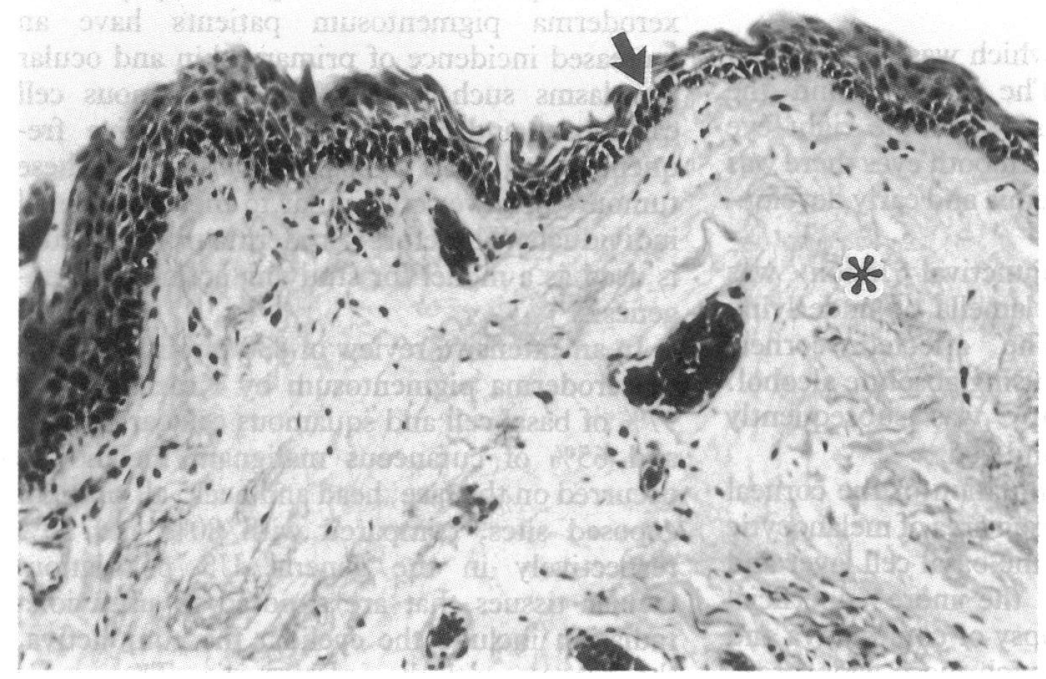

Figure 5 Examination of the biopsy of conjunctiva and limbus showed intraepithelial basilar nests of atypical melanocytes typical of primary acquired melanosis with atypia (arrow). Note the subepithelial elastotic degeneration $(\star)$.

cases the clinical and histological findings of such pre-malignancy complicating xeroderma pigmentosum have to our knowledge not been reported before. The conjunctival and corneal area of precancerous melanosis in the right eye of the 38-year-old Greek woman was treated to prevent further progression into frank malignant melanoma. It is interesting to note that all reported conjunctival melanocytic tumours including our case were located at the 9 o'clock or the 3 o'clock meridian of the limbus which are sites that are least protected from ultraviolet radiation.

The finding of four conjunctival malignant melanomas in a total of 830 published cases of xeroderma pigmentosum is suggestive of an increased frequency of this malignancy. Johnson et $a l^{13}$ calculated that the finding of three patients with uveal melanoma in these 830 cases represents at least 23 times the expected number of cases. Henkind and Benjamin ${ }^{19}$ estimated the frequency of conjunctival melanomas in comparison with uveal melanoma at 1:20-30. Thus the finding of four conjunctival melanomas represents approximately 750 times the expected number.

Ultraviolet radiation as a causative factor in malignant melanoma has been widely debated ${ }^{2021}$ but the finding of an increased frequency of conjunctival melanocytic (pre)malignancies in xeroderma pigmentosum patients strongly implicates a role of sunlight exposure in the malignant transformation of conjunctival melanocytes.

Dr A D A Paridaens was supported by grants from Foundations Fonds ter Bevordering van de Gezondheidszorg, De Drie Lichten and Rens Holle, The Netherlands.

1 Hebra F, Kaposi M. On diseases of the skin. London: New Sydenham Society, 1874; 3: 252 .

2 Reese AB, Wilber IE. The eye manifestations of xeroderma pigmentosum. Am $\mathcal{F}$ Ophthalmol 1943; 26: 901-11.

3 Bellows RA, Lahav M, Lepreau FJ, Albert DM. Ocular manifestations of xeroderma pigmentosum in a black family. Arch Ophthalmol 1974; 92: 113-7.

4 Saebo J. Xeroderma pigmentosum with affection of the eye. $\mathrm{Br}$ fOphthalmol 1948; 32: 398-411.

5 Giller H, Kaufmann WC. Ocular lesions in xeroderma pigmentosum. Arch Ophthalmol 1959; 62: 158-61.

El-Hefnawi $\mathrm{H}$, Mortada A Ocular manifestations of xeroderma pigmentosum. Br $\mathscr{f}$ Dermatol 1965; 77: 251-76.

Sevel D. Xeroderma pigmentosum with ocular complications. BrF Ophthalmol 1963; 47: 687-9.

8 Kraemer KH, Lee MM, Scotto J. Xeroderma pigmentosum: cutaneous, ocular, and neurologic abnormalities in 830 published cases. Arch Dermatol 1987; 123: 241-50.

9 Cleaver JE. Defective repair replication of DNA in xeroderm pigmentosum. Nature 1986; 218: 652-6.

10 Pawsey SA, Magnus IA, Ramsay CA, Benson PF, Giannelli F. Clinical, genetic and DNA repair studies on a consectuve series of patients with xeroderma pigmentosum. $Q \mathcal{J} M e d$ 1979; 48: 179-210.

11 Gulati GC, Ahluwalia BK. Ocular involvement in xeroderma pigmentosum. F All-India Ophthalmol Soc 1967; 15: 233-5.

12 Jensen OA. Xeroderma pigmentosum observed in a Greenlander. Report of a case complicated by malignant melanoma of the conjunctiva. Acta Ophthalmol (Kbh) 1962; 40: 96-103.

13 Johnson MW, Skuta GL, Kincaid MC, Nelson CC, Wolte JR. Malignant melanoma of the iris in xeroderma pigmen tosum. Arch Ophthalmol 1989; 107: 402-7.

14 Kitagawa $K$, Oishi $T$, Inoue $M$. Choroidal malignant melanoma occurring in a patient with xeroderma pigmentosum. Folia Ophthalmol fpn 1981; 32: 657-63.

15 De Wolff-Rouendaal D. Xeroderma pigmentosum with ophthalmological symptoms. Ophthalmologica 1976; 173: 290-1.

16 Folberg R, McLean IW, Zimmerman LE. Primary acquired melanosis of the conjunctiva. Hum Pathol 1985; 16: 129-35.

17 Epstein JH, Fukuyama K, Reed WB, et al. Defect in DNA synthesis in skin of patients with xeroderma pigmentosum demonstrated in vivo. Science 1970; 168: 1477-8.

18 Cleaver JE. DNA damage and repair in light sensitive human skin disease. F Invest Dermatol 1970; 54: 181-95.

19 Henkind P, Benjamin V. Conjunctival melanocytic lesions. Trans Ophthalmol Soc UK 1977; 97: 373-7.

20 Egan KM, Seddon JM, Glynn RJ, Gragoudas ES, Albert DM Epidemiologic aspects of uveal melanoma. Surv Ophthalmol 1988; 32: 239-51.

21 Gallagher RP, Elwood JM, Rootman J, Spinelli JJ, Hill GB, Threlfall WJ, et al. Risk factors for ocular melanoma: Western Canada melanoma study. FNCI 1985; 74: 775-8. 